\title{
MÁQUINA DO ABANDONO: UM OLHAR SOBRE A OBRA CADEIA: RELATOS SOBRE MULHERES, DE DEBORA DINIZ
}

\author{
ABANDONMENT MACHINE: A LOOK AT CADEIA: RELATOS SOBRE \\ MULHERES, BY DEBORA DINIZ
}

\author{
Andreia Marreiro Barbosa ${ }^{1}$ \\ Silvana Maria Pantoja dos Santos ${ }^{2}$
}

\section{RESUMO}

O presente estudo analisa a realidade de mulheres encarceradas, a partir das interfaces entre prisão e vida social na obra Cadeia: relatos sobre mulheres, de Debora Diniz (2015). Tem-se como foco dois espaços que se intercambiam: o presídio, espaço físico de onde a narradora testemunha o cotidiano das presas, as condições do lugar e o tratamento que elas recebem nos ambientes autorizados à sua circulação e o espaço social, contexto de suas vivências exteriores revelado nos relatos. Diante dessas mulheres que historicamente vivenciam dramas e desenvolvem papéis impostos a elas socialmente, questionamos: quem são essas mulheres? Que desejos as movem? Tais indagações partem de um processo que envolve categorias de classe, raça e gênero, relações de dependência, falta de acesso à educação e violência.

Palavras-chave: Mulher. Prisão. Debora Diniz.

\begin{abstract}
This paper analyzes the living conditions of imprisoned women, based on the interfaces between prison and social life portrayed in the book Cadeia: relatos de mulheres, by Debora Diniz (2015). We focus on two interchangeable spaces: the prison, physical space where the narrator witnesses the daily life of the women, the treatment received by them and the conditions of the place; and the social space, where the external experiences revealed in the women's stories take place. We ask: who are these women? What are their innermost desires? These questions arise from a process that involves class, race and gender categories, dependency relations, lack of access to education, and violence.
\end{abstract}

Keywords: Woman. Prison. Debora Diniz.

\footnotetext{
${ }^{1}$ Atualmente é Professora de Direito - UESPI. Doutoranda em Direitos Humanos e Cidadania - UnB. e - mail: andreiamarreiro@hotmail.com

2 Atualmente é Professora Universidade Estadual do Piauí - UESPI e da Universidade Estadual do Maranhão UEMA. Pós-doutora nos estudos da Memória e suas interfaces com a Literatura pelo Programa de Pós-graduação em Memória: linguagem e sociedade da Universidade Estadual do Sudoeste da Bahia - UESB (PROCAD AM/CAPES). e-mail: silvanapantoja3@gmail.com
} 


\section{Debates Insubmissos}

Revista

\section{INTRODUÇÃO}

Refletir sobre a realidade de mulheres encarceradas implica pensar sobre suas vidas, com foco no lugar que as aparta do social e em outro, exterior, de onde vieram. Isso é possível porque o espaço institucionaliza-se como estrutura não somente física, mas também social, sendo este construído por meio de vivências particulares e coletivas. Desse modo, propomos analisar a realidade de mulheres encarceradas a partir das interfaces entre prisão e vida social, tendo como objeto de análise a obra Cadeia: relatos sobre mulheres, de Debora Diniz (2015a). O trabalho pauta-se na pesquisa qualitativa, de cunho bibliográfico, de forma a propor caminhos interdisciplinares. Nos termos de Bastos (2016), a pesquisa qualitativa se dispõe a revelar elementos e aspectos relevantes que não são percebidos de maneira visível, embora estejam presentes e intervenham na configuração dos fenômenos.

São pertinentes as concepções teóricas de Diniz e Paiva (2014) e Ramos (2012) que discutem normas e condutas sociais que constituem o drama humano vivido em presídios; as considerações de Foucault (2003) sobre espaços desviantes; Tuan (2013) acerca da relação entre espaços e percepção, dentre outros não menos importantes.

Os procedimentos metodológicos do trabalho compreendem três etapas: a primeira consiste na apresentação de Debora Diniz, autora da obra Cadeia e de sua atuação na defesa de melhores condições de vida de mulheres em situação de vulnerabilidade; a segunda, compreende a apresentação da obra, com foco na estrutura da narrativa e reflexão sobre o modo como a narradora apreende o espaço prisional; a terceira, envolve a análise das condições de vida das mulheres encarceradas, a partir da obra, objeto de análise; por fim, nas reflexões conclusivas serão compartilhados os achadas da pesquisa que, antes de trazerem respostas engessadas, abrem-se ao diálogo.

A obra retrata a realidade de mulheres encarceradas no Presídio Feminino do Distrito Federal (PFDF), com base nos registros de uma narradora-testemunha que se posiciona nos espaços do presídio permitidos à sua circulação. Neste trabalho interessa-nos saber quem são essas mulheres, como são seus modos de vida dentro e fora da prisão e que desejos e necessidades as movem. Tais questionamentos partem de informações que a obra oferece e 
envolvem categorias de classe, raça e gênero, com implicações na dependência econômica, afetiva e emocional, violência e falta de acesso à educação.

A obra é constituída de narrativas curtas que relatam sobre o cotidiano das mulheres encarceradas, histórias de suas vidas relacionadas a drogas, maternidade e dores do corpo e da alma. São narrativas que podem ser lidas encadeadas ou isoladas. A narradora apoia-se em detalhes percebidos ou relatados pelas próprias presidiárias ou por funcionários da instituição prisional, com os quais convivera durante a sua estada ali. Ressaltamos que, mesmo diante dos eventuais operadores de identificação com os fatos em si, a narrativa não traduz total referencialidade, considerando se tratar de relatos. Estes, ao serem registrados, passam pelas impressões de um $e u$ exterior aos acontecimentos. Isso corrobora para situar o discurso entre o real e o ficcional, tornando frágeis tais limites, de modo a polemizar o efeito de naturalização autor/narrador. Assim, adotaremos o termo "narradora" em vez de "autora", ao longo deste trabalho, por entender que a voz autoral não se confunde com a do eu que se enuncia na tessitura textual.

\section{DEBORA DINIZ E A PESQUISA COM MULHERES: PERCORRENDO CAMINHOS}

Ao compartilhar resultado de pesquisa, Diniz afirma: "escrevo porque sou pesquisadora e minha audiência são minhas colegas acadêmicas. Escrevo para publicar artigos e livros, para ser reconhecida como autora confiável. Escrevo para ser lida” (DINIZ, 2015b, p. 104). A afirmação amplia-se na própria dimensão do texto e ultrapassa os limites do público acadêmico. Sendo feminista e militante dos direitos humanos, a pesquisadora coloca-se na escuta de vozes de mulheres invisibilizadas e se faz audível por sujeitos outros, para além da academia, que acolhem as histórias que sua voz anuncia.

Diniz é doutora em antropologia, professora da Faculdade de Direito da Universidade de Brasília (UnB), escritora e documentarista. É pesquisadora da Anis - Instituto de Bioética, Direitos Humanos e Gênero. A autora tem uma vasta produção acadêmico-científica com ênfase 


\section{Revista \\ Debates Insubmissos}

no feminismo e nos direitos humanos, em que reivindica a alteridade de mulheres vítimas do sistema social. Entre elas, destacam-se as pesquisas relacionadas ao aborto no Brasil, em que divulga dados da magnitude da prática no país, bem como problematiza a sua ilegalidade. Preocupa-se com suas consequências, sobretudo para as mulheres pobres, que apelam para procedimentos rudimentares e arriscados, comprometendo, na maioria das vezes, suas vidas precárias. Diniz tem também se dedicado, nos últimos tempos, a pesquisas com mulheres vítimas do Zika Vírus.

Dos trabalhos da escritora envolvendo mulheres em confronto com a lei, destacam-se o artigo "Mulheres e prisão no Distrito Federal: itinerário carcerário e precariedade da vida" (2014), publicado em coautoria com Juliana Paiva. Nesse trabalho, as autoras analisam o perfil de mulheres encarceradas em regime fechado. Põem em questão o aprisionamento e suas interfaces com a realidade social a que as mulheres são sujeitas, o que denominam de precariedade da vida. São mulheres pertencentes a camadas menos favorecidas que desempenham papéis sociais sob o jugo de uma hierarquia predominante, regulada pelas desigualdades de gênero e pela carência de oportunidades sociais.

O referido artigo e a obra Cadeia resultam de pesquisas desenvolvidas por Diniz, em 2012, no PFDF - único presídio feminino da capital do país. Embora apresentem abordagens semelhantes, as duas pesquisas têm desdobramentos diferentes. No primeiro trabalho, Diniz aborda um fazer pesquisa pautado em critérios objetivos, próprios da ciência moderna, concentrando-se em coleta de dados estatísticos em dossiês, censos e entrevistas sobre a situação sociodemográfica das mulheres. Assim, "Mulheres e prisão no Distrito Federal" apresenta dados do censo de 2012 que revelam um aumento considerável de mulheres encarceradas a partir dos anos 2000. Os números chegam a ser surpreendentes, fazendo com que o Distrito Federal passe a ocupar o $13^{\circ}$ lugar no ranking nacional de mulheres presas.

Em 2005, a população carcerária feminina no DF era de 340 mulheres e correspondia a $2 \%$ da população carcerária feminina nacional. Em 2012, eram 641 mulheres, uma taxa corresponde a 41,2 por 100 mil mulheres no DF (superior à média nacional de 31,4 ) e um crescimento acumulado de $89 \%$, sendo o DF o décimo terceiro no ranking nacional em magnitude populacional de mulheres presas. O presídio atual comporta 504 presas, mas abriga 641 mulheres, ou seja, 27\% mais que sua capacidade (DINIZ; PAIVA, 2014, p. 7). 


\section{Revista \\ Debates Insubmissos}

O aumento do encarceramento feminino suscitou um olhar crítico das pesquisadoras não somente sobre o sistema prisional, mas também sobre as condições de suas vidas. São mulheres de baixa escolaridade ou analfabetas, a maioria negras, situação regulada pela hierarquia social excludente. Sem perspectivas de ascensão social, as mulheres assumem funções informais ou se mantêm sem trabalho, engrossando as estatísticas do desemprego.

Decorrente de suas pesquisas etnográficas com mulheres em confronto com a lei, destaca-se o artigo "Cadeia de papel”, onde DINIZ (2015c) expõe os resultados da sua pesquisa desenvolvida no Reformatório Feminino de Adolescentes, em Brasília. Diniz descreve o método utilizado no trabalho, mas esclarece que "a escrita pode ser confrontada com aquelas que vivem as histórias como sujeitas de pesquisa” (p. 107). Então, subverte a investigação acadêmica clássica no instante em que compartilha com as adolescentes os registros de suas histórias marcadas por violência. As meninas, sujeitas da pesquisa, passam então a serem partícipes da escrita, pois avaliam, renegam, sugerem alterações no processo de elaboração textual.

Cadeia tem um diferencial em relação aos demais trabalhos etnográficos de Diniz. Talvez a pesquisa que resultou no artigo "Mulheres e prisão no Distrito Federal" e a que desencadeou "Cadeia de papel" tenham suscitado em Diniz um modo peculiar de compreender a precariedade da vida de mulheres encarceradas. Ou talvez tenham suscitado nela o desejo de aproximar as linhas das vidas das mulheres para pensar nos pontos que as interseccionam (reformatório/prisão) e, depois, desdobrá-las por uma via mais aproximada, em que as mulheres pudessem ser ouvidas, sentidas, percebidas, sem que isso diminuísse o valor do trabalho de pesquisa.

DINIZ (2015a) informa que, a princípio, concentrava sua investigação em dados resultantes de questionários e anotações colhidas nos prontuários das presas, cujo quantitativo a deixava incomodada pela crueza, que gerava um fosso entre pesquisadora e pesquisadas. Foi então que conseguiu autorização para frequentar o Núcleo de Saúde da instituição, o que favoreceu uma aproximação com as mulheres. Pôde, então, não só acompanhar as ocorrências das presas no setor, como também testemunhar os pormenores de suas histórias de vida. 
Cadeia é, portanto, resultado de seu experimento linguístico, em que o fazer científico é traduzido em prosa não menos acadêmica, pela leveza da linguagem e pelas impressões depositadas nos fatos testemunhados e observados.

\section{CADEIA: ESTRUTURA NARRATIVA E DIMENSÃO DO ESPAÇO PRISIONAL}

A prisão constitui-se o fulcro da ação narrada, um espaço que, por si só, reverbera limitação, anulação da mobilidade e liberdade que repercutem no estado emocional, desencadeando sentimento de apinhamento que, nos termos de Tuan (2012), é aquele espaço privativo de liberdade ou que provoca tal sensação. Assim, a espacialidade da obra Cadeia retrata as tensões, a partir das relações que as mulheres detentas estabelecem com/no lugar de clausura.

A referida obra constitui-se de 50 registros, pequenos capítulos independentes, em que os relatos vão sendo compartilhados por uma narradora que se coloca na condição de escutadeira de vozes abafadas pelos muros do presídio. O espaço de atuação é o Núcleo de Saúde do presídio, destinado aos atendimentos médico, psicológico e de assistência social. Para preservar a identidade das presas, a narradora utiliza nomes fictícios, colhidos nos próprios arquivos do presídio. "A realidade do presídio rejeita sinônimos, mas autoriza semelhanças", diz a narradora (DINIZ, 2015a, p. 12).

O primeiro e o último capítulos denominados de "Início" e "Fim" são revestidos de subjetividade, na medida em que comportam impressões da narradora sobre o espaço prisional, as explicações acerca dos procedimentos da pesquisa (que teve duração de seis meses), a descrição de como se deu o contato, a convivência com os funcionários da instituição carcerária e as reflexões sobre as vidas ali amontoadas. Apesar do distanciamento tomado por ela ao longo dos demais capítulos, expressões como "demorei para entender", "mas percebo", "só agora vejo", "descobri que", “doía ouvir", "talvez ainda mais escutar sem entender" denotam a não passividade do olhar. A perplexidade ante o mundo que se desdobra à sua frente anuncia um modo diferente de ver o que já era costumeiro. 


\section{Revista \\ Debates Insubmissos}

A percepção tem início no corpo através dos sentidos (tato, audição, visão, paladar e olfato), e vai se consolidando por meio da relação entre o sujeito e os espaços. A percepção dos espaços do presídio vai variando de acordo com o senso crítico da narradora e os seus sentidos, sendo a visão a base da geometria projetiva. Seu olhar diante do novo modo de ver projeta-se primeiramente de modo amplo, por meio de uma visão caleidoscópica, para, em seguida, identificar os ângulos, as especificidades dos lugares da prisão, cuja visão os atraem ou repelem em graus variados.

O mundo do presídio é identificado pelas cores: a branca é usada pelos profissionais do Núcleo; a preta, pelos que fazem a segurança; a laranja, pelas presidiárias que, em meio à massa, invisibilizam-se nos seus uniformes. Ao adentrar o Núcleo, passam à condição de sujeitas e assumem outra identidade. A ida ao Núcleo ocorre quando necessitam de um atendimento específico; as recém-chegadas, denominadas de provisórias, passam pelo espaço para triagem. São inquiridas pelos profissionais da saúde e assistência social sobre os descaminhos da vida exterior: uso de drogas ilícitas, medicamentos, contatos familiares para eventuais necessidades.

A capa do livro instiga uma reflexão sobre o sentido do lugar: com um fundo preto, contrasta com a cor branca impressa no nome da autora, no título e na ilustração composta por seis linhas paralelas, que sugere uma grade suspensa no ar. Essa visão coaduna-se com a ideia de prisão: um espaço silencioso e imóvel, que serve para abrigar e isolar, e de onde se obedece ao comando da disciplina e da ordem.

A percepção humana impõe presença ao lugar, assim, a postura e posição de quem observa/narra define o ambiente espacial, já que o homem, por meio da sua percepção e suas impressões, é quem mede a localização e distância. A narradora da obra Cadeia encontra-se no centro, ou seja, no comando da narrativa, e acaba dando as direções de proximidade/distanciamento das cenas narradas. Assim, o espaço frontal do presídio, visto à distância, recebe as coordenadas do corpo.

Torre do presídio da capital federal é despotismo: janelas espiadoras, sala rica em telas, antenas e rádios. A torre tem lentes para o pátio, a Rodoviária e Ala C. Pátio é chão grande de cimento. [...] A Rodoviária é telhado de zinco, instalação militar dura, única sombra do pátio (DINIZ, 2015a, p. 21). 


\section{Revista \\ Debates Insubmissos}

A narradora capta, com crueza, a fachada e os primeiros compartimentos que o olhar abarca. A cercadura do presídio com torre antropomorfizada que espia, seguida de microespaços sem adornos e sem vivacidade. Com uma pincelada de ironia fina, a narradora enfatiza: "sala rica em telas, antenas e rádios" e torres com lentes a serviço de vigilância.

A prisão representa a ruptura do contato do homem com o mundo, o que pode ser enquadrada como espaço heterotópico. FOUCAULT (2003) diz que as heterotopias constituemse de diferentes lugares classificados de acordo com os papéis desempenhados socialmente ${ }^{3}$. No entendimento dele, ao contrário dos espaços utópicos que definem o homem em relação à sociedade, os heterotópicos são espaços operantes que se firmam pela confrontação, muitas vezes subvertendo ou transgredindo os lugares da ordem, podendo oscilar entre heterotopia de crise e de desvio. A tensão entre os espaços da ordem social e da des/ordem provoca uma dinâmica sobre a qual se estrutura a narrativa de Cadeia.

Foucault classifica de heterotopia desviante ou contraespaço os lugares que segregam, apartam. A prisão, então, pode ser classificada como um contraespaço, posto que sitiado, "fora de todos os lugares" (FOUCAULT, 2003, p. 20). A prisão aparta os que ameaçam a ordem social. Daniel Defert (2013) ao revisita o conceito de heterotopia de Foucault assevera que os contraespaços não deixam de ser "interpenetrados por todos os outros espaços que eles contestam". Acrescenta DEFERT (2013, p. 38):

Eles são apreendidos em uma sincronia e uma diacronia específicas que fazem deles um sistema significante [...]. Não refletem a estrutura social nem a da produção, não são sistema sócio-histórico nem uma ideologia, mas rupturas da vida ordinária, imaginários, representações polifônicas da vida, da morte. (DEFERT, 2013, p. 38)

O espaço prisional aproxima-se de outros lugares heteróclitos, como o espelho, cemitério, casa de tolerância, dentre outros. São espaços-tempos, "lugares onde estou e não estou; ou onde sou outro. Eles ritualizam cortes, limiares, desvios" (DEFERT, 2013, p. 37).

\footnotetext{
${ }^{3}$ Heteros (diferentes) remete a alter (outro), e topia, a espaço/lugar: "lugar do outro".
} 


\section{Revista \\ Debates Insubmissos}

Além de espaço heterotópico, na obra Cadeia podemos caracterizar o presídio também como espaço social, pela sua condição de lugar constituído de relações, por mais inóspito que pareça. O Núcleo de Saúde revela-se esse lugar com indicações de relações, por conseguinte, de materialidade humana. As presidiárias depositam sobre as profissionais da saúde e assistência social seus dramas, conflitos, afetos, desejos, medos e dores. Tanto é que a narradora preocupa-se menos com as características físicas do Núcleo, do que com o modo como o mesmo é vivenciado.

Em planos simultâneos, vão sendo acolhidas cenas cotidianas interiores, do dentro, e exteriores, do fora ${ }^{4}$ Como uma rede que liga pontos e entrecruza a trama, interior e exterior, presente e passado, próximo e longínquo, obscuro e iluminado, a narradora vai deixando entrever os dramas das mulheres nas duas esferas, como também as suas impressões sobre os fatos testemunhados. O intercâmbio de cenas encaminha o leitor para a exegese de um espaço ambíguo, contracenando com os dois regimes do olhar: interior e exterior.

A obra revela que o espaço prisional feminino apresenta nuances relacionadas à subjetividade das mulheres, o que favorece a diferenciação entre o cárcere feminino do masculino. Com isso, abordar necessidades cotidianas que envolve desde o cuidado com o corpo e a saúde até a maternidade. Revela também questões complexas, como o modo como as mulheres se envolvem com as drogas.

\section{VIDAS SITIADAS NA OBRA CADEIA}

Logo no início da obra, a narradora anuncia que fora pesquisadora antes de escritora e que, nesse processo, entrevistas, arquivos e publicações fizeram e fazem parte de suas atividades. Essa informação torna-se salutar porque potencializa o que anuncia em seguida: “pelos números, soube que uma em cada quatro presas viveu em reformatórios na adolescência, muitas sofreram violência, usaram drogas, roubaram coisas e sobreviveram perambulando pelas ruas" (DINIZ, 2015a, p. 9). Em seguida, acrescenta que as mulheres que adentram o presídio

\footnotetext{
${ }^{4}$ Do dentro e do fora são expressões usadas no presídio para indicar os espaços interior e exterior, respectivamente.
} 
"são multidão anônima e qualquer: no acolhimento, se personalizam pela desgraça de fora" (DINIZ, 2015a, p. 14).

Nas reflexões da narradora ao final da obra, somos impactados com uma constatação, síntese das hipóteses levantadas no início: a de que "o presídio é a máquina do abandono para a qual os sentidos da violência são múltiplos" (DINIZ, 2015a, p. 210). Atando as pontas, vemos que a máquina do abandono abrange também o contexto social, já que a degradação das mulheres se dá pelas condições de suas vidas miseráveis, fechadas em si mesmas, sem perspectiva de ascensão social.

São mulheres marcadas por tragédias cotidianas e necessidades; mulheres sitiadas que convivem com o desprezo, a indiferença e a falta de perspectiva. A sociedade imprime sobre elas seu poder punitivo, criminalizando-as em uma ação em prol do combate eficaz "à criminalidade (o mal), a ser instrumentalizada pelas funções da pena: uma combinatória de retribuição ou castigo com prevenção geral" (ANDRADE, 2012, p. 134). Acrescenta Andrade:

É nesse campo que se exacerba o maniqueísmo criminal, o fortalecimento de um nós contra o outro, "outosideres antecipados", e a radical relação de exterioridade que os "cidadãos de bem" mantêm para com a problemática criminal, então fortemente moralizada. [...] Velhos e novos inimigos internos e externos da sociedade (ANDRADE, 2012, p. 166, grifo da autora).

Assim, a sociedade desenvolve um mecanismo de controle visando a defesa e proteção do cidadão de "bem", o que Andrade denomina de mecanismo informal. Tal mecanismo parte de diferentes segmentos, como família, escola, trabalho, e se dilata pelas mídias, fortalecendose para manter esses sujeitos cada vez mais apartados.

Trata-se de um clamor punitivo que não poupa nem juventude nem adolescência, mas a demanda por sua criminalização é, naturalmente, para os filhos dos outros (não para os nossos), para os filhos da rua, órfãos de pai e de mãe, órfãos do Estado, e que se pretende agora adotados pela prisão (ANDRADE, 2012, p. 167).

Segundo dados de 2012 do Sistema Integrado de Informações Penitenciárias (INFOPEN) sobre a população carcerária, $68 \%$ das mulheres presas são negras. Essa realidade é reiterada na obra Cadeia, cuja narradora constata, in loco, que a maioria das mulheres já julgadas ou em regime provisório, além de negras, são jovens, analfabetas ou com baixa escolaridade e vindas de espaços excludentes, o que dificulta suas expectativas de inserção no 
mercado de trabalho. As estatísticas mostram que o presídio feminino apresenta um contingente significativo de mulheres negras e pobres, vítimas do processo de segregação e exclusão. Em geral, elas exercem ou exerciam trabalho informal, majoritariamente atividades precárias.

O lugar da mulher encarcerada é marcado por fatores econômicos e perpassa pela mentalidade social dominante. São mulheres subalternizadas, discriminadas em razão da etnia, da classe e do gênero e desprezadas pela sociedade. São mulheres que resistem em uma sociedade que as ignora, resultando em sobrevivências miseráveis. Assim, o mecanismo de segregação gera um tipo de população que circula por todos os espaços, exatamente porque não tem, de fato, nenhum espaço.

Diante dessa realidade, inquietamo-nos em busca de respostas sobre quem são essas mulheres e que vidas tinham antes do cárcere. A pesquisa de Diniz e Paiva (2014), por meio das estatísticas, adianta-nos sobre o perfil de suas vidas miseráveis:

São mulheres jovens (51\% têm menos de 30 anos), pretas e pardas (67\%), pouco escolarizadas $(71 \%$ com ensino fundamental incompleto ou menos que o fundamental), trabalhadoras domésticas e informais (70\%) ou desempregadas (18\%), com pelo menos um filho (80\%) e com companheiros presos $(52 \%)$, e envolvidas com infrações relacionadas ao tráfico de entorpecentes (69\%). Das mulheres com menos de 30 anos, $52 \%$ estudaram apenas até o ensino fundamental, ou seja, têm, em média, menos de 7 anos de estudo (DINIZ; PAIVA, 2014, p. 10).

A máquina do abandono social articula-se com a prisional e, juntas, mantêm a assepsia, justificada em nome da proteção do grupo do "bem”. Na obra Cadeia, são muitos os relatos que justificam tal máquina, reproduzida em diferentes tragédias humanas.

A negligência da família, do Estado e da sociedade acarreta a vulnerabilidade de crianças e adolescentes. Devido a essa realidade, muitas acabam envolvendo-se com a ilegalidade. A história de Tatiana retrata essa condição:

Tatiana invadiu delegacia aos sete anos. Não era ainda bandida, mas vítima. Não foi ouvida, saiu como menina levada, o pai cuidadoso tinha texto pronto para delegado, "Ela insistiu em mentir e fugir de casa". De uma surra, foi internada em UTI; de outra, fratura exposta, o braço guarda cicatriz. [...] O bando era nômade e extenso. O pai, líder do crime familiar, seguia teoria própria: quanto mais filhos, melhor para a caça diária (DINIZ, 2015a, p. 181-182, itálico nosso).

A condição de vulnerabilidade de Tatiana é acarretada pela desassistência familiar e, o que é mais grave, o pai foi responsável por sua inserção na criminalidade, sem que a menina 
Revista

Debates Insubmissos

tivesse chances de se esquivar. Diniz e Paiva (2014) informam que mulheres jovens, pouco escolarizadas e com histórico de internações na infância e adolescência em reformatórios é um fato comum nos presídios:

uma em cada quatro das mulheres sentenciadas em regime fechado passou por medidas socioeducativas de internação na adolescência. Há um itinerário carcerário iniciado na juventude, em que os períodos fora da prisão foram como recessos na rotina vigiada pelas instituições totais. ${ }^{5}$ Por itinerário carcerário, entendemos a vivência das mulheres em instituições punitivas e de controle penal por determinação judicial que exigem afastamento compulsório das atividades quotidianas e das relações familiares ou afetivas (2014, p. 14-15).

O abandono é caracterizado, dentre outros fatores, pelo distanciamento de parentes próximos. Mulheres que visitam mulheres no presídio, em geral, são amigas. Os filhos não são frequentes nas visitas, muitos aparecem somente em dias festivos. $\mathrm{O}$ fato de ter uma mulher da família presa é, muitas vezes, motivo de vergonha, o que justifica as ausências e contribui para o agravamento da solidão. A narradora se dá conta dessa realidade com certa perplexidade: "só agora vejo a raridade dos visitadores. Eles têm gênero na gramática da sobrevivência: são mulheres visitando mulheres. Pensei que as visitadoras eram parentes, mães, irmãs ou filhas presas. Descobri que a estatística do presídio traía minha percepção [...]” (DINIZ, 2015a, p. 102, itálico nosso).

Visita íntima em presídio feminino não tem o mesmo grau de regularidade que no masculino. $\mathrm{O}$ fato de muitos companheiros estarem também na prisão favorece a escassez. Outro fator que acarreta o abandono é o fato de muitas mulheres terem parentes próximos, que constituem o núcleo familiar, também na prisão - em muitas situações, por causa da economia das drogas. "Nesse sentido, não são apenas mulheres ou homens típicos, mas famílias extensas as que vivenciam a experiência do aprisionamento no gerenciamento das relações familiares e do cuidado com os filhos" (DINIZ; PAIVA, 2014, p. 12).

A partir dos anos 2000, tem sido constatado um aumento significativo de mulheres nas prisões. Um dos grandes vilões desse efetivo é o negócio das drogas: “de 2005 a 2010 houve

\footnotetext{
${ }^{5}$ Em termos estritamente normativos, a medida socioeducativa de internação não é uma pena de reclusão, pois não cabe a tipificação de crimes e penas para crianças e adolescentes. No entanto, o itinerário carcerário representa a trajetória em espaços de punição para o controle do crime ou de práticas ilegais.
} 


\section{Revista \\ Debates Insubmissos}

um aumento de $227 \%$ no encarceramento de mulheres por tráfico de drogas, superior aos índices masculinos, que foram de 205\%" (RAMOS, 2012, p. 65).

Muitas mulheres são detidas quando tentam entrar em presídios com entorpecentes para seus homens ou para homens desconhecidos, como forma de negócio; outras, por assumirem o posto de venda de drogas após a prisão do companheiro. Ramos assevera que

Quem lida com a realidade carcerária sabe que a maioria das mulheres presas por tráfico referencia um homem, seja aquele que pediu a ela que levasse a droga, seja porque o marido foi preso ou morto ou porque precisou ser sucedido na administração da "boca de fumo" ou dos negócios. Muitas mulheres assumem os negócios por necessidade de manter a família, sejam aquelas que apenas estavam no local do flagrante, quando da prisão do companheiro, tal fato revela uma mudança no perfil das mulheres presas por tráfico (RAMOS, 2012, p. 90).

Além da relação de mulheres com as drogas, decorrente do envolvimento afetivo, há outra situação que envolve aquelas marcadas pelo consumo do crack: “[...] trapo humano, tudo estava queimado e encardido no couro, o cabelo raro [...] (DINIZ, 2015a, p. 57); “[ ...] a pele era engelhada como papel velho amassado" (p. 114). Nessas e em outras descrições, a narradora acentua a referência ao nariz carcomido pelos efeitos da droga. São mulheres frágeis, de magreza esquálida, perfil que vai ao encontro de seus modos vida: moradoras de rua ou de lixões, que perambulam muitas vezes com crianças até serem capturadas pelo sistema prisional e verem seus filhos ter outros destinos.

O presídio de mulheres carrega as marcas da subjetividade feminina, sendo a maternidade o lado mais sensível. As mulheres, em geral, têm prole numerosa, em torno de cinco a oito filhos. Ao serem presas, confiam-nos a familiares mais próximos: "casa de avó é asilo de netos" (DINIZ, 2015a, p. 74). Já as mulheres que têm seus filhos na prisão vivem o dilema da separação. A lei permite a permanência da criança no convívio com a mãe até os 6 meses de idade. Se o presídio tiver estrutura para o acolhimento de crianças, com creche, por exemplo, o tempo poderá ser dilatado até os 7 anos, mas não é o caso do PFDF.

Ela chorava em posição de procedimento. Olhos caídos, queixo no peito, o nariz fungando a parede. O colete preto amoleceu-se com a mãe, atarantou-se com a ordem de algema para trás. Os dedos compridos balançavam uma fralda branca, úmida e amassada pelo choro. Ela se fazia de sozinha, mas nós éramos multidão. Colete preto e jaleco branco estavam ali para a despedida de Rayane, a bebê de seis meses em adeus ao presídio. [...] 'Dói tanto, d. Jamila' (DINIZ, 2015a, p. 37-39). 
A partida da criança nascida no presídio é sempre dolorosa, informa Diniz. O sentimento de acolhida da pequena Rayane fez com que a multidão de mulheres se desdobrasse em afagos e cuidados para com a criança. Essa sensibilidade atingiu também os funcionários e funcionárias do presídio.

Diferente de Rayane, Samir, que também nasceu em clausura, permaneceu na companhia da mãe até 1 ano de idade, protelado pela equipe do Núcleo de Saúde.

O pequeno Samir era de idade muda, barulho era de choro ou riso. [...] A mãe deu para chorar, e o menino risonho tremia o queixo. A entrega de Samir foi decretada, abrigo ou nova família, Laila escolheria destino. A data estava no calendário, o futuro era logo. [...] O dia da despedida é triste, o seguinte é miserável: não há deserto maior que o primeiro dia sem o filho. Quem parte não é só a criança de berço: junto se vai o sentido da sobrevivência de uma mulher parida na prisão (DINIZ, 2015a, p. 111).

Quando da permanência do filho no presídio, as presas ficam na Ala A, espaço com melhores condições para o bem-estar das crianças. Encerrado esse convívio, retornam às alas comuns, perdendo "as poucas regalias conquistadas" (DINIZ, 2015a, p. 111).

A obra relata mais uma história de cisão entre mãe e filho, a do pequeno Artur, apartado do pai pelo presídio. Só o vira uma única vez, graças ao "bonde do amor que se move entre os presídios" (DINIZ, 2015a, p. 130). A criança permaneceu no presídio por 11 meses e chegara a hora de conhecer outro mundo. A guarda da criança fora designada pela justiça à madrastaavó. No dia da partida, "o lugar era triste. Não houve alvoroço de despedida, o menino-rei se foi com pressa" (DINIZ, 2015a, p. 132).

A maternidade gera desassossego entre as mulheres encarceradas: causa dor, quando os filhos são apartados de si; angústia, quanto se recusam a visitá-las; culpa, quando estão em abrigos; insegurança, quando são obrigados a amadurecer antes do tempo para cuidar dos irmãos menores; intranquilidade, quando se encontram sob a guarda de pessoas não confiáveis. É o caso de Dayane, cujos filhos estão sob a "proteção" do sogro e sofrem espancamentos da tia. O cartão do auxílio-reclusão permanece com o sogro, que tem a guarda condicionada ao benefício. O marido está preso por violência doméstica. Diante desse quadro, Dayane não tem escolha. A vida gira em círculo, a intranquilidade persiste: "mudança de guarda, notificação ao Conselho Tutelar" (DINIZ, 2015a, p. 119), o que mais aterroriza as mulheres encarceradas. 


\section{Revista \\ Debates Insubmissos}

“Conselho Tutelar é pior que polícia, vigia criança alheia, e império é maior que o da lei. É a moral batendo à porta ignorando se há reinado doméstico" (DINIZ, 2015a, p. 118).

Assim, percebe-se que o espaço que as mulheres ocupam socialmente carrega a marca dos contraespaços. São mulheres que deslizam às margens da conjuntura social, prisioneiras da sua própria sorte.

\section{CONCLUSÕES}

Cadeia conduziu-nos para dentro de um presídio feminino, possibilitando-nos conhecer a realidade de mulheres encarceradas, com suas histórias no espaço prisional e as interfaces com suas vidas costuradas socialmente.

Segundo a legislação pátria, a execução penal tem como objetivo promover a reintegração social da pessoa condenada, inibindo a ocorrência de novas infrações. Nessa conjuntura, a pessoa presa deve não só receber um tratamento adequado, como também ter uma assistência efetiva, pois, do contrário, torna-se difícil a readaptação social.

O PFDF é marcado pela superlotação, falta de acesso à saúde e educação, ausência de atividades para as presas e de espaço apropriado para lazer e visitas íntimas, entre outras carências que corroboram para o fortalecimento da máquina do abandono. Essa realidade distancia-se das condições carcerárias proclamadas pela Organização das Nações Unidas, pela Constituição Federal, pela Lei de Execução Penal e pelos tratados internacionais com os quais o Brasil assumiu compromissos referentes ao tratamento das pessoas presidiárias.

Embora os nomes das personagens de Cadeia sejam constructos linguísticos corporificados em prontuários, as mulheres são reais e suas histórias coadunam-se com as de tantas outras aprisionadas por suas vidas precarizadas. As mulheres encarceradas encontram-se multiplamente excluídas e estigmatizadas. Muitas unidades femininas constituem-se de alas e celas adaptadas, sem qualquer tipo de infraestrutura adequada para mulheres, como creche ou berçários. 
Como agravante, a maioria é de baixa renda e de escolaridade precária. As mulheres são, em geral, mães solteiras que arcam sozinhas com as responsabilidades do lar e dos filhos. Antes de ser encarceradas, encontram-se desempregadas ou trabalham informalmente, situações que sintetizam a precariedade de suas vidas. Quando presas, são abandonadas pelos companheiros e familiares, tendo que confiar a guarda dos filhos a parentes, conhecidos, vizinhos. Com o ingresso na prisão, recebem a cicatriz de delinquente, que se perpetuará mesmo após o alcance da liberdade.

Diante de uma sociedade seletiva e desigual, as mulheres das camadas menos favorecidas são marcadas pela cisão social: com a falta de perspectiva e de melhores condições de vida, veem-se vulneráveis a situações adversas que propiciam a prática de ações delituosas. A sociedade imprime, então, o seu poder punitivo sobre aquelas que se mantêm fora da ordem e dos princípios da moral vigente, sob a égide dos discursos proferidos na esfera dos microssistemas. Desse modo, o binarismo fora (vida social) e dentro (prisão) exerce um campo de forças na combinatória do castigo.

\section{REFERÊNCIAS}

ANDRADE, Vera Regina Pereira de. Pelas mãos da criminologia: o controle penal para além da (des)ilusão. Rio de Janeiro: Revan; ICC, 2012.

BASTOS, Maria Clotilde Pires. Metodologia científica. Rio de Janeiro: Editora: Do autor, 2016.

BRASIL. Ministério da Justiça. Sistema Integrado de Informações Penitenciárias. InfoPen Estatística: 2005-2014. Disponível em: <http://www.justica.gov.br/seus-direitos/politicapenal/documentos/infopen_dez14.pdf>. Acesso em: 3 fev. 2020.

DEFERT, Daniel. Heterotopia: tribulações de um conceito entre Veneza, Berlim e Los Angeles. In: Michel Foucault: o corpo utópico, as heterotopias. Trad. Salma Tannus Muchail. São Paulo: N-1 Edições, 2013.

DINIZ, Debora. Cadeia de papel. Revista Liberdade, ed. 19, 2015c. Disponível em: <http://www.revistaliberdades.org.br/site/outras>. Acesso em: 3 fev. 2020. 
DINIZ, Debora. Cadeia: relatos sobre mulheres. Rio de Janeiro: Civilização Brasileira, 2015a.

DINIZ, Debora. Pesquisas em cadeia. Revista Direito GV, vol. 11, n. 02, p. 573-586, jul.dez. $2015 b$.

DINIZ, Debora; PAIVA, Juliana. Mulheres e prisão no Distrito Federal: itinerário carcerário e precariedade da vida. Revista Brasileira de Ciências Criminais, v. 111, p. 313-328, 2014.

FOUCAULT, Michel. Outros espaços. In:

Ditos e escritos III - estética: literatura e pintura, música e cinema. Tradução: Salma Tannus Muchail. São Paulo: n-1, 2003. p. 19-30.

RAMOS, Luciana de Souza. Por amor ou pela dor? Um olhar feminista sobre o encarceramento de mulheres por tráfico de drogas. Dissertação (mestrado) - Universidade de Brasília, Brasília, 2012.

TUAN, Yi-Fu. Espaço e lugar: a perspectiva da experiência. Tradução: Lívia de Oliveira. Londrina-PR: EDUEL, 2013. 